Research Article

\title{
Preliminary Assessment of a Fire Escape Hood Integrated with Positioning and Motion Sensors
}

\author{
Małgorzata Okrasa $\mathbb{D}^{1},{ }^{1}$ Emil Kozlowski $\mathbb{D}^{2},{ }^{2}$ and Rafal Mlynski $\mathbb{D}^{2}$ \\ ${ }^{1}$ Department of Personal Protective Equipment, Central Institute for Labour Protection-National Research Institute, Wierzbowa 48, \\ Łódź 90-133, Poland \\ ${ }^{2}$ Department of Vibroacoustic Hazards, Central Institute for Labour Protection-National Research Institute, Czerniakowska 16, \\ 00-701 Warsaw, Poland
}

Correspondence should be addressed to Małgorzata Okrasa; maokr@ciop.lodz.pl

Received 15 February 2021; Accepted 6 August 2021; Published 24 August 2021

Academic Editor: Everardo Vargas-Rodriguez

Copyright (c) 2021 Małgorzata Okrasa et al. This is an open access article distributed under the Creative Commons Attribution License, which permits unrestricted use, distribution, and reproduction in any medium, provided the original work is properly cited.

\begin{abstract}
Wearable electronics appear more frequently in the personal protective equipment market (PPE) primarily to assure information and alarm functions for the user. However, despite their advantages, there remain doubts concerning the level of protection that these devices can guarantee and their conformity to requirements laid down in PPE legislation. This paper investigates the factors that need to be assessed to confirm that such devices function correctly under anticipated use conditions. To this end, we considered a case study of an air-purifying fire escape respirator (APER) integrated with a radio-based positioning system and alarming device. In particular, we examined the parameters associated with the operation of the alarm and the information functions (the visibility and audibility of the alarm signals and the radio signal strength of the positioning system). This study provides evidence that the anticipated use conditions and the APER construction have a combined effect on the correct functioning of the embedded electronics. Based on these findings, we identified additional requirements that should be considered by PPE manufacturers at the design stage as well as by health and safety practitioners when evaluating the protection levels of PPE with embedded electronics.
\end{abstract}

\section{Introduction}

The use of dangerous chemicals is necessary for some industry sectors vital for technologically advanced society, such as general chemicals manufacturing, petrochemical and oil refineries, processing metals, or plastic and rubber manufacturing. Within the EU alone, around 12 thousand establishments use such substances, posing a major industrial accident threat. Every year, over 30 such accidents are reported [1]. As a result, fires, explosions, or the release of dangerous chemicals used in technological processes may occur, resulting in enormous economic losses and disruption of sustainable growth. In order to limit the associated hazards, appropriate measures are required to prevent major accidents and ensure the most accurate response in the event of such accidents. European leg- islation regulates the prevention of such accidents and specifies the rules for limiting their consequences for human health and the environment within the so-called Seveso III Directive [2]. According to its requirements, when a major accident occurs, there is a necessity to implement internal emergency plans in the establishment, including an immediate evacuation of employees from the facility.

In such situations, the use of appropriate personal protective equipment (PPE) may be of critical importance. Due to the nature of chemical substances used in facilities posing a threat of a major industrial accident, it is vital to protect workers against the effects of smoke and toxic combustion products absorbed into the body through the respiratory tract by providing them with appropriate emergency escape respirators. Various such devices are available on 
the market, starting from complicated ones such as selfcontained open or closed-circuit breathing apparatus to simple ones like self-rescuers from carbon monoxide with mouthpiece assembly or air-purifying respirators (APR) with hoods.

The last ones are among the most widespread due to their small size and lightweight construction, making them quick and easy to don even by inexperienced users. They protect against the two most common types of hazards, which present a high risk to the human respiratory system, that is, against carbon monoxide poisoning and respiratory exposure to specific chemicals (vapors or gases). They also provide head and face protection against thermal radiation and flame and eye protection against irritation associated with fumes and toxic combustion products. Equipment used for personal protection should comply with basic requirements for safety and health, as specified in the (EU) 2016/425 regulation of the European Parliament and Council of 9 March 2016 [3]. The EN 403:2004 standard is the primary document in this respect [4]. It contains a description of the requirements, test methods, and markings for APR escape hoods intended for rescue from a fire. Following the provisions of this standard, equipment may only be accepted if its components meet all the requirements set out in the test regulations.

The specifics of the hazards that may occur in emergencies may vary; for these reasons, it is difficult to predict all aspects that may hinder the evacuation process, posing a threat to worker safety [5]. In these cases, passive respiratory protective devices may not be satisfactory to limit the risk sufficiently. Therefore, technological progress in information and communication technologies (ICT) should be leveraged to develop new protective devices (so-called smart PPE) that improve the efficiency of evacuation by active means $[6,7]$. Systems and techniques that enable ongoing monitoring of the localization of individuals evacuating a building and systems generating audible and visual alarms [8-12] are of particular importance. Nevertheless, no specific requirements or reliable, standardized testing methods for such smart PPE have been introduced [13].

This paper demonstrates the design of an APR with a hood integrated with a radio-based user positioning system and alarming device (LPW module). Challenges associated with its development and future implementation in a harsh and dynamically changing work environment will be discussed in terms of factors that need to be assessed before confirming that such devices function correctly under anticipated conditions of use. In particular, we describe the results of the evaluation of the impact of the equipment use conditions on the correct operation of the equipment's alarm and information functions, i.e., (i) the sound pressure level of the acoustic signal emitted by the alarming device in the vicinity of the hood user, depending on his/her body position; (ii) the strength of the radio signal received by the scanning device from the integrated LPW modules depending on the user's body position; and (iii) the speed of finding the user in simulated fire conditions (simultaneous subjective and objective assessment of visibility and audibility of alarm signals).

\section{Materials}

As a base, we used an air-purifying respirator (APR) with a hood protecting against smoke (Maskpol S.A., Poland) compliant with the EN 403 : 2004 standard [4]. In terms of design, the equipment comprises a hood equipped with a panoramic visor, an internal silicon half-mask, and a purifying element (a combined gas filter) selected according to the hazard (Figure 1(a)). Given that the combined gas filter cannot be replaced, the hood is intended for single use only.

An electronic localization and visibility improvement module was integrated into an escape hood (LPW module, Figure 1(b)). The module was developed based on the commercially available Bluetooth Low Energy (BLE) iNode CareSensor \#1 (ELSAT s.c., Poland) equipped with BLE CSR 1010 (Qualcomm Technologies International, Ltd., UK) chipset with $128 \mathrm{~KB}$ recorder and transmitter working between $-18 \mathrm{dBm}$ and $+8 \mathrm{dBm}$ range, a three-axis accelerometer enabling positioning with respect to ground level and a temperature sensor with a resolution of $1^{\circ} \mathrm{C}$ and operation range of -30 to $65^{\circ} \mathrm{C}$. Technical documentation is available free of charge at the manufacturer's website (ELSAT s.c., Poland).

For the purpose of this study, the module was equipped with an acoustic signaling device, LEDs, and an additional battery (type: 14250, 1/2 AA). The total mass of the module was less than $20 \mathrm{~g}$, including battery and $3 \mathrm{D}$ printed casing with a diameter of $40 \mathrm{~mm}$ and height of $15 \mathrm{~mm}$.

The module's functions included (i) emitting BLE radio signals to determine the approximate location of the APR user (available only when the network connection was working properly) and (ii) generating sound and light alarms in case the user stops moving or the temperature in their vicinity is too high (independent from the network connection). The accelerometer threshold was set at $0.02 \mathrm{~g}$, activating the alarm whenever the acceleration of such value was not detected, while the temperature threshold was set at $40^{\circ} \mathrm{C}$. Remote configuration of the module was possible using the generally available iNodeSetup software (ELSAT s.c., Poland).

The LPW module could work in two modes, i.e., standby mode (active when APR was not in use) and alarm mode (activated after the user donned the APR). In the alarm mode, the device's status was sent online at fixed intervals $(0.32 \mathrm{~s})$ in a broadcast frame and could be received by any BLE scanning device within its range. In the standby mode, the battery working life was up to 3 years (which corresponded to the APR shelf life), and in the alarm mode, 20 to $30 \mathrm{~min}$. (which corresponded to the combined gas filter service life).

Four integration variants were used to determine the optimal positioning of the LPW module on the surface of the hood (Figure 2). A method of indirect connection of components consisting of fitting electronic modules in 3D printed casing was used for the integration. As a reference variant (RV), an escape hood without the module was used.

\section{Methods}

3.1. Determining the Sound Pressure Level of the Signal Emitted by the Alarming Device. The sound pressure level 


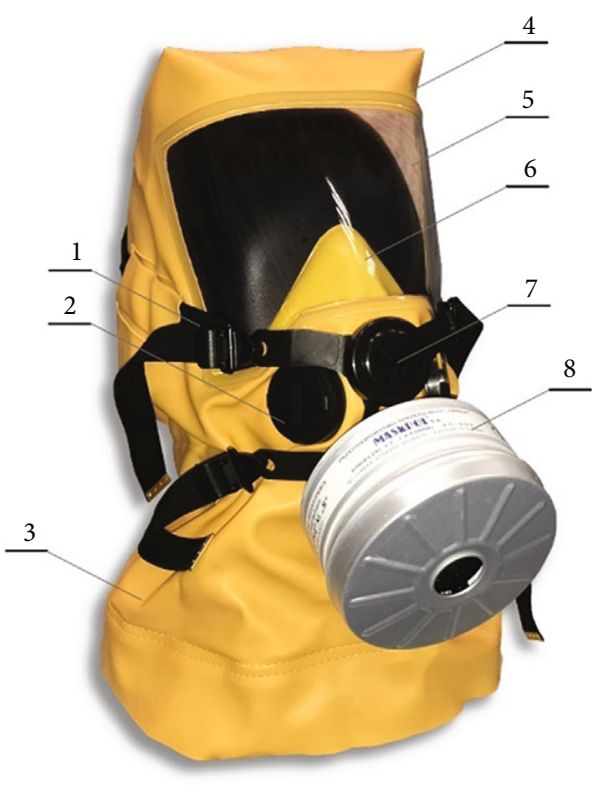

(a)
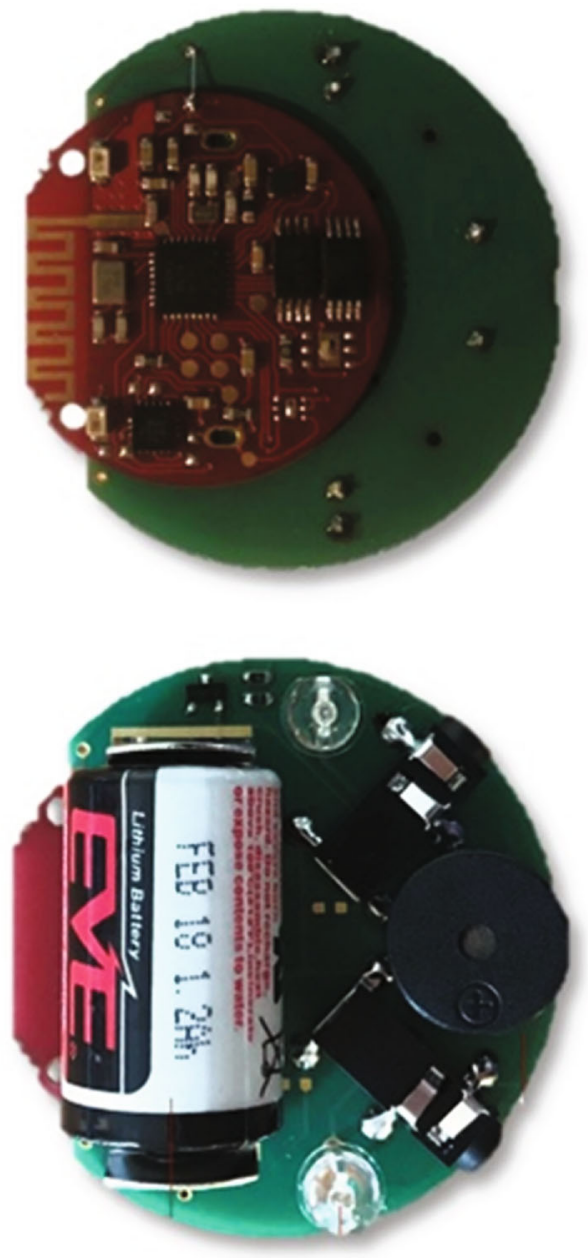

(b)

FIGURE 1: (a) APR with hood protecting against smoke for emergency escape from a fire: 1-head harness, 2-exhalation valve, 3-silicone neck seal, 4-hood, 5-visor, 6-inner half-mask, 7-speech diaphragm, and 8-combined gas filter; (b) LPW module (front and back).

produced by the acoustic signaling device of the LPW module in the surroundings of the hood user was tested in an acoustic chamber at the Tech-Safe-Bio CIOP-PIB Laboratories. The tests were performed using an iNodeLan scanning device connected to the local LAN network and LPW module placed in the casing integrated into the construction of the APR escape hood. Before testing, the user fitted the escape hood with an LPW module working in the alarm mode. Subsequently, the user adopted one of the three variants of body position simulating the positions during evacuation (Table 1). For each study participant's body position (P1P3), the tests were carried out with the LPW module placed in one of the four locations (L1-L4, Figure 2). In addition, the tests were performed in the absence of the module (control measurement; RV), during which the background noise parameters were ascertained.

The studies were performed using a Svan 948 (SVANTEK, Poland) sound level meter located on a tripod at $3 \mathrm{~m}$ distance from the head of the participant and at $1.55 \mathrm{~m}$ height above the ground (the height was determined based on the ISO 9612: 2009 standard concerning methods for determining occupational noise exposure [14]). A-weighted sound pressure level result was recorded. The elementary result was obtained during a measurement lasting 30 seconds. For each measurement variant, the test was performed six times.

3.2. The Determination of the Attenuation of the Radio Signals Emitted by the LWP Module. Testing the level of radio signal attenuation was performed using an iNodeLan scanning device connected to the local LAN network and an LPW module placed in the casing and integrated into the construction of the escape hood at locations L1-L4 (Figure 2). Before testing, the user fitted the escape hood with the LPW module working in the alarm mode. Subsequently, the user adopted one of the three positions (P1P3), analogous to the ones described for sound level testing (Table 1), and remained motionless for the entire duration of the experiment.

The iNodeLan scanning device was placed at a $3 \mathrm{~m}$ distance from the participant's head (marked by the blue dot in Figure 3) in one of the four locations (marked by red dots in Figure 3). The measurements were repeated for each location (red dot), starting from the initial one (marked with 'START') and ending at the final one (marked with 'STOP'). 


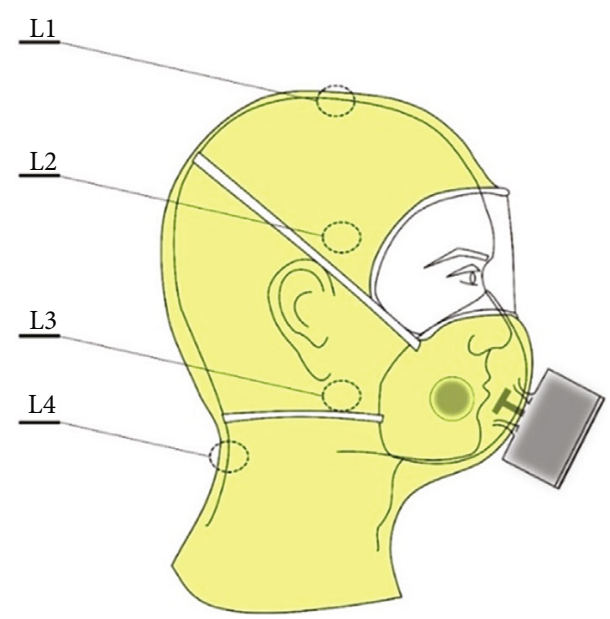

FIGURE 2: The variants of LPW module integration into the escape hood: L1-the module positioned centrally in the axis of the body; L2-the module positioned on the left temple above the top band of the head harness; L3 - the module positioned on the left cheek beneath the bottom band of the head harness; L4-the module positioned at the nape of the neck on the left side beneath the bottom band of the head harness.

The reading of the received signal strength indicator (RSSI) was carried out for 3 minutes at a frequency of $10 \mathrm{sec}-$ onds for each integration variant at the transmitting power set to the level of Tx equal to $+2 \mathrm{dBm}$. Each measurement was repeated four times.

\subsection{The Ease of Finding the Hood User in Conditions} Simulating Fire. We assessed the ease of finding the hood user in conditions simulating fire (smoke up to a height of $1.8 \mathrm{~m}$, noise, fire, and evacuation light simulation) in the State Fire Brigade smoke chamber at the Rescue Firefighting Unit No. 2 in Łódź (Figure 4). Six experienced firefighters (aged 29 to 45 , work experience of 2 to 19 years), who participated daily in rescue and firefighting actions, participated in the study.

Before performing the test, the escape hood equipped with the LPW module (placed only in location L1, Figure 2) was fitted onto a head model simulating an unconscious victim. Next, the model was placed in one of the four positions in the smoke chamber (two outside and two within the obstacle course). The study participant's task was to find the head model as soon as possible without prior knowledge of its position. The study was performed in two variations: (i) with the LPW module working in the alarm mode and (ii) without the module (RV). The test result was the time measured from entering the chamber by the participant until reaching the head model.

Following each test, participants filled out a short survey in which they assessed the difficulty of reaching the victim (question 1), audibility of the sound signal (question 2), and visibility of light signals (question 3). The response to each attitudinal question followed the five-point Likert scale, as follows: "very low," "low," "average," "high," and "very high" [15]. Each variant was evaluated by six participants twice, totaling 12 responses for each variant.

\section{Results and Discussion}

4.1. The Sound Level Emitted by the Alarming Device. Aweighted sound pressure level values (the average of the six elementary test results) generated by the LPW module for the various body positions of the participant and module locations on the surface of the escape hood are shown in Figure 5. In addition, statistical analysis was performed to determine the significance of the differences among the integration variants and study participant body positions. The results are shown in Table 2.

The A-weighted sound pressure level in the chamber, obtained during the reference variant testing (RV, lack of LPW module), equaled $19.7 \mathrm{~dB}$ and was less than half the level typical of office rooms. Following the activation of the alarming device, a significant increase in sound pressure level was observed, depending on both the integration variant and the body position of the escape hood user (statistically significant differences between various positions and integration variants; Table 2). A-weighted sound pressure level measured during use of the acoustic signaler exceeded by at least $20 \mathrm{~dB}$ the value of background noise. Such a considerable signal-tonoise distance guaranteed that the conditions in the test room did not affect the measurement results. Independently of the integration variant, the highest A-weighted sound pressure level was recorded for position P1. This followed from the lack of physical obstacles between the LPW module, i.e., the sound source and the sound level meter. In the other two cases, depending on the integration variant, the acoustic signal was limited due to the obstruction of the direct path of the acoustic wave by the limbs or other body parts of the study participant.

For the $\mathrm{P} 1$ position, the highest A-weighted sound pressure level values were obtained for the L1 variant, while the lowest were obtained for the L3 and L4 variants. In these cases, varying sound pressure level values arose from the diverse locations of the LPW module with respect to the microphone of the sound level meter. For the L1 variant, the module plane (in which the acoustic signaling device was placed) was positioned at an acute angle to the plane of the microphone membrane of the sound level meter. For L2 and L3 variants, the planes were positioned perpendicularly to each other, while for L4, the module plane and the microphone membrane plane were positioned parallel to each other, although, unlike the L1 variant, the signal was emitted away from the microphone position. For the $\mathrm{P} 2$ position, the highest $\mathrm{A}$-weighted sound level values were obtained for the L2 and L3 variants because the module was placed on the side of the head and was not obscured by the user's body parts, whereas they were the lowest for the L4 variant. The module location in the nape area caused a reduction in sound pressure level. For the $\mathrm{P} 3$ position, the highest A-weighted sound pressure level values were obtained for the L1 variant (the module was not obstructed), and the lowest were obtained for the remaining variants, in which the module was positioned between the floor and the user's head (L2 and L3) or was partially obstructed by the hood's fabric folded on the nape of the study participant's neck (L4). 
TABLE 1: Study participant's body positions.

Body position variant

P1

Upright sitting position, arms relaxed, hands joint, and placed on the thighs

P2

Supine position, body fully extended, arms relaxed at a $45^{\circ}$ angle with respect to the body axis

P3

Prone position, body fully extended, head in the left lateral position, arms relaxed and flexed, placed around the head

Photograph
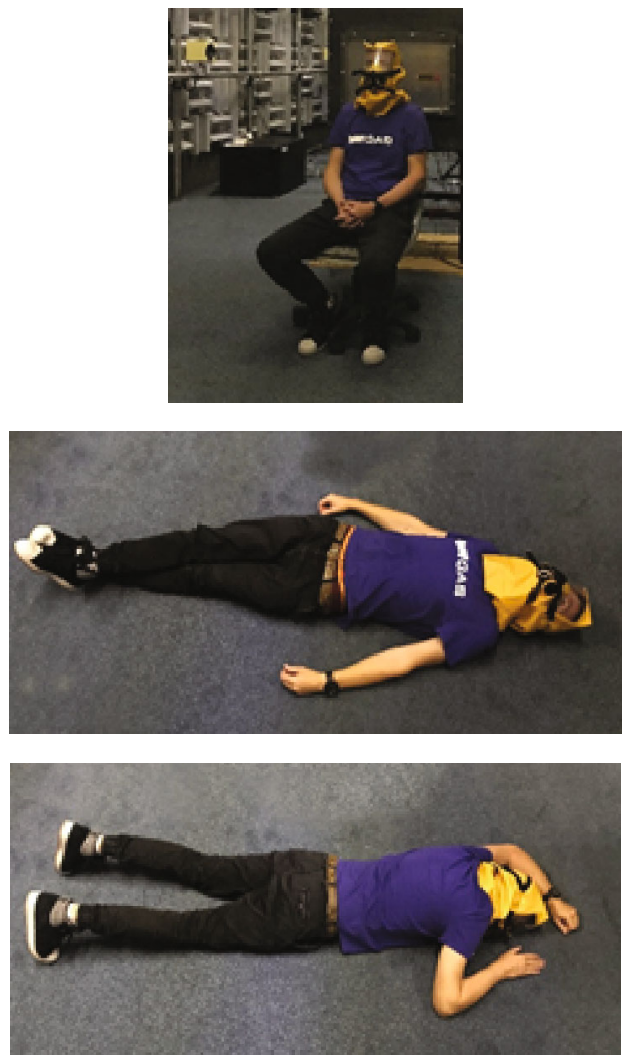

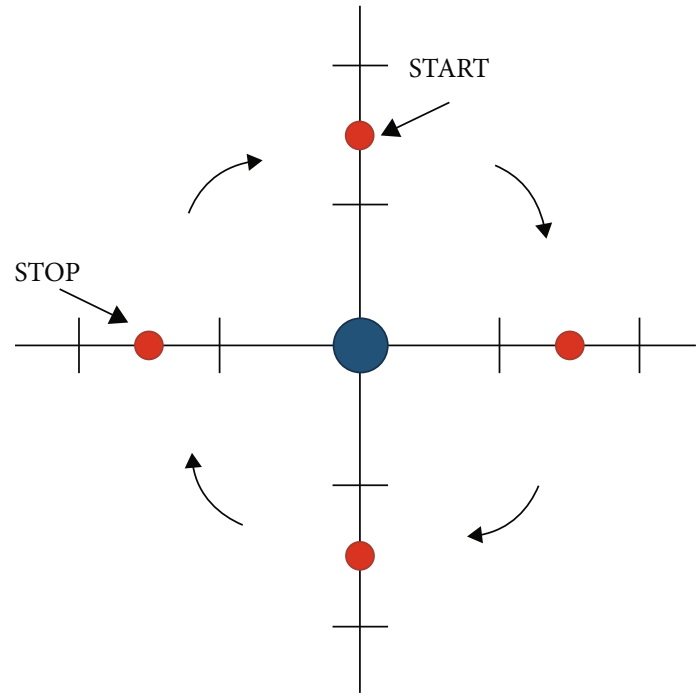

FIGURE 3: The distribution of the measurement points (red dots) for the analysis of radio signal attenuation by the user's body (blue dot).

The trends described above agree with the results of measurements concerning the attenuation of acoustic signals generated by personal alert safety systems (PASS) described

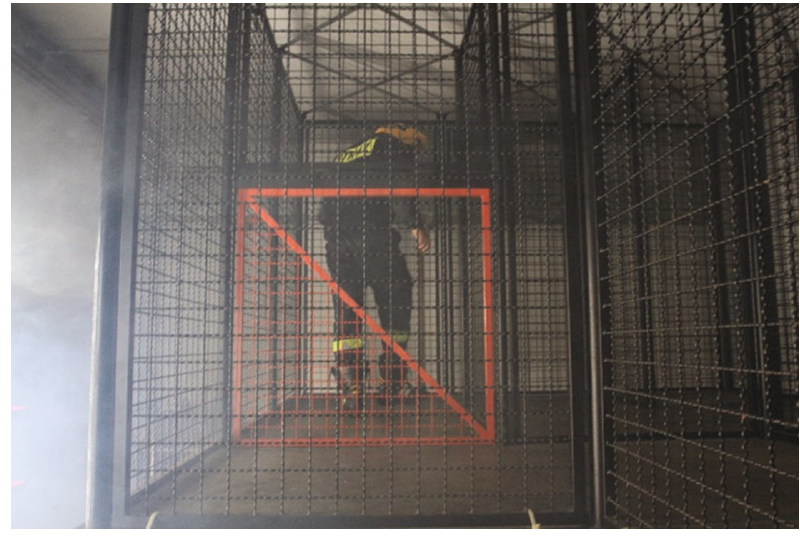

FIgURE 4: The view of the study participant in the smoke chamber.

in the literature [16]. This suggests a significant impact of appropriate positioning of alarming devices with respect to the audibility of alarm signals and the dependence of the user's body positions on the measured sound pressure level of such signals. Considering all of these results, the L1 integration variant was the most advantageous in terms of the highest A-weighted sound pressure level values that could potentially be translated into subjective audibility of alarm 


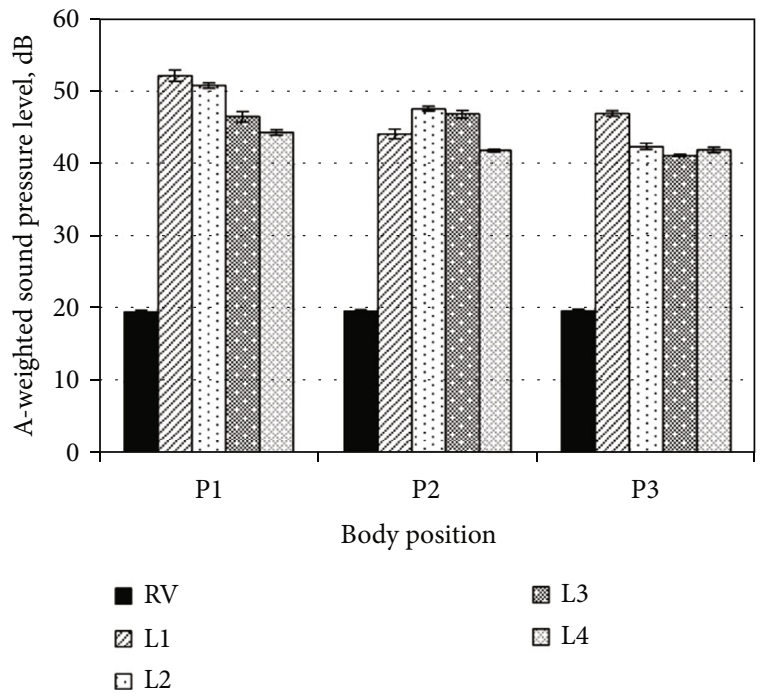

Figure 5: A-weighted sound pressure level values at a preestablished distance from the alarming device for each integration variant and the user's body position; $\mathrm{P} 1$ - sitting position, $\mathrm{P} 2$ - supine position, P3-prone position. L1-L4-LPW module locations; RV: reference variant. Error bars represent one standard deviation.

signals by individuals conducting rescue operations. In this variant, the LPW module was not obstructed independently of the study participant's body position. It has to be mentioned that the A-weighted sound pressure level values measured were lower than the values required by the NFPA1982 standard for the PASS devices [17] (92 dB at $1 \mathrm{~m}$ distance).

Moreover, they did not meet the requirement concerning safety sound signals specified in the EN ISO 7731 standard that recommends that the A-weighted sound pressure level not be lower than $65 \mathrm{~dB}$ [18]. One must bear in mind that the solution developed here is not intended for use by firefighters and is not a sound source for danger signals described in the EN-ISO 7731 standard [18]. It is also important to remember that the scope of the study did not include obtaining the highest possible A-weighted sound pressure level values emitted by the LPW module; instead, the scope covered the comparison of various positions on the hood and determination of the situation most advantageous in terms of the potential audibility of the alarm.

\subsection{The Attenuation of the Radio Signal Emitted by the LPW} Module. The attenuation of the radio signal generated by the LPW module in various body positions and the localizations of the module on the hood surface are presented in Figure 6. Table 3 shows the statistical analysis results performed to ascertain the significance of the differences between individual integration variants.

Like the sound signal, the radio signal attenuation depended on the body position in which it was tested and on the integration variant. Despite high variability of the individual measurement results (high values of standard deviation, Figure 6), statistically significant differences between RSSI values were obtained for each body position regardless of the integration variant and differences between integration variants for most positions (Table 3 ).
TABLE 2: Statistical analysis of the A-weighted sound pressure level for each module integration variant and body position.

\begin{tabular}{|c|c|c|c|c|}
\hline \multirow[b]{2}{*}{$\begin{array}{l}\text { Integration } \\
\text { variant }\end{array}$} & \multirow[b]{2}{*}{ Parameter } & \multicolumn{3}{|c|}{ A-weighted sound pressure level (dB) } \\
\hline & & $\begin{array}{l}\text { P1 body } \\
\text { position }\end{array}$ & $\begin{array}{l}\text { P2 body } \\
\text { position }\end{array}$ & $\begin{array}{l}\text { P3 body } \\
\text { position }\end{array}$ \\
\hline \multirow{4}{*}{ RV } & M & $19.7^{* A}$ & $19.7^{* A}$ & $19.7^{* A}$ \\
\hline & SD & 0.3 & 0.3 & 0.3 \\
\hline & Max & 20.0 & 20.0 & 20.0 \\
\hline & Min & 19.2 & 19.2 & 19.2 \\
\hline \multirow{4}{*}{ L1 } & $\mathrm{M}$ & $52.2^{* B}$ & $44.1^{\# B}$ & $46.9^{\$ B}$ \\
\hline & SD & 0.7 & 0.7 & 0.4 \\
\hline & $\operatorname{Max}$ & 53.4 & 45.0 & 47.5 \\
\hline & Min & 51.4 & 43.3 & 46.5 \\
\hline \multirow{4}{*}{$\mathrm{L} 2$} & M & $50.8^{* C}$ & $47.6^{\# C}$ & $42.4^{\$ C}$ \\
\hline & SD & 0.4 & 0.3 & 0.4 \\
\hline & Max & 51.2 & 48.0 & 42.8 \\
\hline & Min & 50.1 & 47.3 & 41.8 \\
\hline \multirow{4}{*}{ L3 } & M & $46.5^{* D}$ & $46.9^{* D}$ & $41.1^{\# D}$ \\
\hline & SD & 0.7 & 0.5 & 0.2 \\
\hline & $\operatorname{Max}$ & 47.2 & 47.3 & 41.4 \\
\hline & Min & 45.4 & 46.0 & 41.0 \\
\hline \multirow{4}{*}{ L4 } & $\mathrm{M}$ & $44.4^{* E}$ & $41.9^{\# E}$ & $41.9^{\# C}$ \\
\hline & SD & 0.4 & 0.2 & 0.4 \\
\hline & Max & 44.8 & 42.1 & 42.3 \\
\hline & Min & 43.9 & 41.6 & 41.5 \\
\hline
\end{tabular}

M: mean value; SD: standard deviation; Max: maximum; Min: minimum; P1: sitting position; P2: supine position; P3: prone position; L1-L4: LPW module locations; RV: reference variant; *, \#, \$: statistically significant differences occur for means marked with different signs within a given row (ANOVA, $\alpha=0.05$; Tukey's test, $\alpha=0.05$ ); A- statistically significant differences occur for means marked with different signs within a given column (ANOVA, $\alpha$ $=0.05$; Tukey's test, $\alpha=0.05$ ).

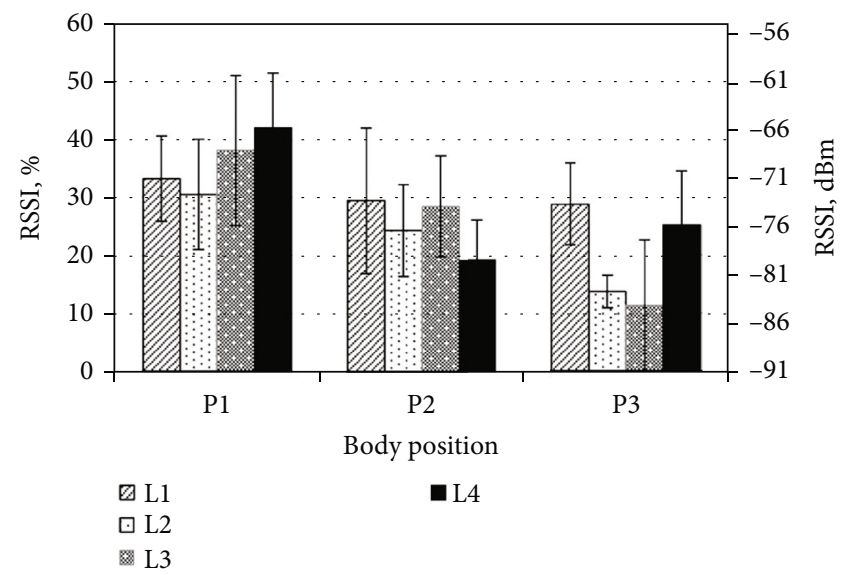

FIgURE 6: The mean RSSI values at $3 \mathrm{~m}$ from the user for each integration variant and body position; P1: sitting position; P2: supine position; P3: prone position; L1-L4: LPW module locations. Error bars represent one standard deviation. 
TABLE 3: The statistical analysis of the RSSI value at $3 \mathrm{~m}$ from the user for each integration variant and body position.

\begin{tabular}{|c|c|c|c|c|}
\hline $\begin{array}{l}\text { Integration } \\
\text { variant }\end{array}$ & Parameter & $\begin{array}{l}\text { P1 body } \\
\text { position }\end{array}$ & $\begin{array}{l}\text { RSSI (\%) } \\
\text { P2 body } \\
\text { position }\end{array}$ & $\begin{array}{l}\text { P3 body } \\
\text { position }\end{array}$ \\
\hline \multirow{4}{*}{ L1 } & $\mathrm{M}$ & $33.2^{\mathrm{A} \#}$ & $29.5^{\mathrm{A} *}$ & $28.8^{\mathrm{B} *}$ \\
\hline & SD & 7.3 & 12.5 & 7.1 \\
\hline & Max & 53 & 53 & 45 \\
\hline & Min & 17 & 5 & 13 \\
\hline \multirow{4}{*}{$\mathrm{L} 2$} & $\mathrm{M}$ & $30.5^{\mathrm{A} \$}$ & $24.3^{\mathrm{C \#}}$ & $13.7^{\mathrm{A} *}$ \\
\hline & $\mathrm{SD}$ & 9.5 & 7.9 & 2.8 \\
\hline & Max & 53 & 40 & 20 \\
\hline & Min & 17 & 5 & 8 \\
\hline \multirow{4}{*}{ L3 } & $\mathrm{M}$ & $38.1^{\mathrm{B} \$}$ & $28.4^{\mathrm{A} \#}$ & $11.3^{\mathrm{A} *}$ \\
\hline & SD & 12.9 & 8.7 & 11.3 \\
\hline & Max & 57 & 45 & 32 \\
\hline & Min & 17 & 17 & 0 \\
\hline \multirow{4}{*}{$\mathrm{L} 4$} & M & $42.0^{\mathrm{B} \$}$ & $19.2^{\mathrm{B} *}$ & $25.2^{\mathrm{B} \#}$ \\
\hline & SD & 9.4 & 6.9 & 9.3 \\
\hline & Max & 57 & 32 & 53 \\
\hline & Min & 23 & 0 & 8 \\
\hline
\end{tabular}

M: mean value; SD: standard deviation; Max: maximum; Min: minimum; P1: sitting position; P2: supine position; P3: prone position; L1-L4: LPW module locations; *, \#, \$: statistically significant differences occur for means marked with different signs within a given row (ANOVA, $\alpha=0.05$; Tukey's test, $\alpha$ $=0.05$ ); A- statistically significant differences occur for means marked with different signs within a given column (ANOVA, $\alpha=0.05$; Tukey's test, $\alpha=0.05$ ).

For the P1 position, the lowest RSSI values were noted for the L2 variant, while the highest values were noted for the L4 variant. Independently of the integration variant, they were higher than the results obtained for the remaining body positions because of the lack of signal obstruction by the user's body parts (on average by $10.6 \% / 6.4 \mathrm{dBm}$ in the $\mathrm{P} 2$ position and $16.2 \% / 9.7 \mathrm{dBm}$ in the $\mathrm{P} 3$ position). In this case, the differences between individual variants resulted from diverse positioning of the LPW module with respect to the scanning device that, in turn, stemmed from asymmetric radio signal propagation. For the P2 position, the highest values of RSSI were recorded for the L1 and L3 variants. This is because the study participant's body parts did not obstruct the module during testing in this position. The lowest values were recorded for the L4 variant because, in this scenario, the transmitter was positioned in the space between the floor and the study participant's head (a decrease of $22.8 \% / 13.7 \mathrm{dBm}$ was observed compared to the same variant in the P1 position). A similar situation occurred when testing L2 and L3 variants in the P3 position. In these cases, the decreases of RSSI compared to the variant in which no module obstruction took place were $16.9 \% / 10.1 \mathrm{dBm}$ and $26.9 \% / 16.1 \mathrm{dBm}$, respectively. The highest values of RSSI, in this case, were obtained for the L1 variant.

According to the literature, screening radio signals by the human body may limit positioning efficiency when using
TABLE 4: The time needed to find the victim in the smoke chamber.

\begin{tabular}{lcc}
\hline Parameter & RV & Time (s) \\
\hline M & $95.79^{*}$ & L1 \\
SD & 66.35 & $75.48^{*}$ \\
Max & 226.37 & 56.84 \\
Min & 27.13 & 219.00 \\
\hline
\end{tabular}

*: lack of statistically significant differences (Student $t$-test, $\alpha=0.05)$. RV: reference variant; L1: APR escape hood equipped with the LPW module placed in position L1; M: mean value; SD: standard deviation; Max: maximum; Min: minimum.

wireless radio technologies [19]. Abdullah and coworkers described an effect of attenuation at the level of 5-10 dBm for wearable BLE devices intended to be carried on the wrist [20]. Faragher and Harle described similar values of RSSI attenuation $(\sim 10 \mathrm{dBm})$ for a positioning system based on BLE called Navsop. For the study results discussed, the L1 variant was the least prone to screening because the location of the scanning device in the majority of the cases prevented the obstruction of the module by the user's body. The literature also describes the effects of RSSI attenuation due to user movements and body proximity [21]; however, for the solution developed, it is impossible to eliminate these factors because the final device application is that of wearable equipment intended for evacuation. An additional factor to consider when choosing an integration variant is the strong dependence of the transmitter antenna orientation with respect to the scanning device antenna on the strength of signal read by the scanning device [22-24]. This effect was visible in our tests, and it may affect the correct operation of the designed solution.

4.3. The Ease of Finding a User under Conditions Simulating Fire. We assessed the ease of finding the hood user under conditions simulating a fire by measuring the time needed to find the victim (the head model fitted with the escape hood) in a smoke chamber. Comparisons of average times measured when testing the reference variant (RV) and the variant equipped with the LPW module are presented in Table 4 . The results indicate a shortening by more than $20 \%$ of the time needed to reach the victim under conditions simulating fire when using the escape hood integrated with the LPW module. We found that the times required to find the victim was highly variable. Because of the small number of participants, it was impossible to measure statistically significant differences for this parameter.

The results of the subjective evaluation of the degree of difficulty of reaching the victim, sound signal audibility, and light signal visibility are shown in Table 5 .

In subjective studies to compare the reference hood variant (RV) to the APR escape hood equipped with the LPW module placed in position L1, participants rated similar difficulties of reaching the victim (question 1). This means that the study conditions were similar in both cases (similar access route and difficulty of reaching the victim). Such an experimental setting constituted the conditions necessary to 
TABLE 5: The subjective evaluation of the degree of difficulty of reaching the victim, audibility, and visibility of the alarm signals.

\begin{tabular}{|c|c|c|c|c|c|c|c|c|c|c|}
\hline \multirow{2}{*}{ Evaluated parameter } & \multicolumn{5}{|c|}{$\mathrm{RV}$} & \multicolumn{5}{|c|}{ L1 } \\
\hline & Very low & Low & Average & High & Very high & Very low & Low & Average & High & Very high \\
\hline The difficulty of reaching the victim (question 1) & 0 & 1 & 7 & 2 & 2 & 0 & 3 & 7 & 1 & 1 \\
\hline Audibility of the sound signal (question 2) & 10 & 1 & 1 & 0 & 0 & 6 & 3 & 2 & 0 & 1 \\
\hline Visibility of light signals (question 3) & 12 & 0 & 0 & 0 & 0 & 0 & 5 & 4 & 3 & 0 \\
\hline
\end{tabular}

RV: reference variant; L1: APR escape hood equipped with the LPW module placed in position L1.

compare the levels of audibility and visibility of the victim/alarming device in the two variants studied.

For the reference variant (RV), most responders indicated very low audibility of signals from the victim (question 2). When using the alarming device (L1), most participants indicated low, medium, or even high audibility. Further modification of the LPW module towards augmenting the signal generated by it should significantly improve audibility with respect to the reference variant. For the subjective assessment of the victim's/alarming device visibility level, the differences between the reference variant (12 responders rated victim's visibility as very poor) and the variant integrated with an LPW module (five responders rated visibility as low, four as medium, and three as very high) were more noticeable. The enhancement of the victim's/alarming device visibility upon LPW module activation means that the light signaling applied was sufficient for the planned application of the designed solution.

\section{Conclusions}

APR escape hoods are explicitly designed for short-duration use (up to $30 \mathrm{~min}$.) if an emergency occurs at the workplace. The dynamic progress in wearable electronics provides exciting opportunities for enriching the functionality of such devices to aid users in obtaining safe egress from dangerous areas. The anticipated conditions of use of such solutions may be meaningful in the context of their correct operation. Of particular significance are factors impacting the equipment's critical information and alarm functions resulting from the specificity of the electronic elements integrated into the hood construction. Nevertheless, currently, a standardization gap exists that makes it impossible to conduct a comprehensive assessment of this type of equipment in terms of the discussed aspects.

The results presented in the present study confirm that the hood's anticipated conditions of use are of great importance in the context of the correct operation of integrated electronic components. We showed that A-weighted sound pressure level and received radio signal strengths depended on the positioning of the electronic elements on the hood surface, the user's body position, and the angle at which the signals reach the measuring devices. We also determined that using light signal-generating electronic elements is an efficient means of increasing the visibility of an escape hood user under conditions similar to those of fire. These properties are essential from the point of view of the functioning of the APR escape hood but are not considered when testing this type of PPE following the relevant standards (i.e., EN $403: 2004$ standard).

We hope that this study will inform health and safety practitioners and PPE manufacturers about the possibilities brought about by applying modern technological solutions in the construction of PPEs. We also seek to advance the knowledge regarding the challenges in evaluating the functionality of such devices.

\section{Data Availability}

The data used to support the findings of this study are included within the article.

\section{Disclosure}

The funders had no role in the design of the study; in the collection, analyses, or interpretation of data; in the writing of the manuscript; and in the decision to publish the results.

\section{Conflicts of Interest}

The authors declare no conflict of interest.

\section{Acknowledgments}

The publication is based on the results of a research task carried out within the scope of the fourth stage of the National Programme "Improvement of safety and working conditions" partly supported in 2017-2019-within the scope of research and development-by the Ministry of Science and Higher Education/National Centre for Research and Development. The Central Institute for Labour Protection- National Research Institute is the Programme's main coordinator. We would like to express our gratitude to the State Fire Brigade at the Rescue and Fire-fighting Unit No. 2 in Łódź and to Mr. Paweł Ćwietkowski (CIOP-PIB) for technical assistance during this research.

\section{References}

[1] European Commission, "EUROPA - eMARS statistics," August 2019, https://emars.jrc.ec.europa.eu/en/emars/ statistics/statistics.

[2] The Europian Parliament and the Council of the Europian Union, "Directive 2012/18/EU of the European Parliament and of the Council of 4 July 2012 on the control of majoraccident hazards involving dangerous substances, subsequently repealing Council Directive 96/82/EC," Official Journal of the European Union L, vol. 197/1, pp. 1-37, 2012. 
[3] The Europian Parliament and the Council of the Europian Union, "Regulation (EU) 2016/425 of the European Parliament and of the Council of 9 March 2016 on personal protective equipment and repealing Council Directive 89/686/EEC," Official Journal of the European Union L, vol. 81/51, pp. 51-98, 2016.

[4] EN 403, 2004 - Respiratory Protective Devices for Self-Rescue. Filtering Devices with Hood for Escape from Fire. Requirements, Testing, Marking, 2004.

[5] M. Kobes, Understanding Human Behaviour in Fire - Validation of the Use of Serious Gaming for Research into Fire Safety Psychonomics, 2010.

[6] D. Podgórski, K. Majchrzycka, A. Dąbrowska, G. Gralewicz, and M. Okrasa, "Towards a conceptual framework of OSH risk management in smart working environments based on smart PPE, ambient intelligence and the internet of things technologies," International Journal of Occupational Safety and Ergonomics, vol. 23, no. 1, pp. 1-20, 2017.

[7] S. Merkel, Building Evacuation with Mobile Devices, KIT Scientific Publishing, Karlsruhe, 2006.

[8] L. Cheng, C. Wu, Y. Zhang, and L. Chen, "A rescue-assist wireless sensor networks for large building," in 2013 IEEE 8th Conference on Industrial Electronics and Applications (ICIEA), pp. 1424-1428, Melbourne, VIC, Australia, June 2013.

[9] G. Bernardini, M. Azzolini, M. D’Orazio, and E. Quagliarini, "Intelligent evacuation guidance systems for improving fire safety of Italian- style historical theatres without altering their architectural characteristics," Journal of Cultural Heritage, vol. 22, pp. 1006-1018, 2016.

[10] H. P. Hsu, K. M. Yu, S. T. Chine, S. T. Cheng, M. Y. Lei, and N. Tsai, "Emergency evacuation base on intelligent digital signage systems," in 2014 7th International Conference on Ubi-Media Computing and Workshops, pp. 243-247, Ulaanbaatar, Mongolia, July 2014.

[11] A. Ferscha and K. Zia, "On the eEfficiency of lifebelt based crowd evacuation," in 2009 13th IEEE/ACM International Symposium on Distributed Simulation and Real Time Applications, pp. 13-20, Singapore, 2009.

[12] M. Okrasa, "Real-time location systems as an evacuation support tool," Prace Naukowe Akademii im. Jana Dtugosza w Czestochowie. Technika, Informatyka, Inżynieria Bezpieczeństwa, vol. 6, pp. 277-293, 2018.

[13] J.-P. Buchweiller, A. Mayer, R. Klein et al., "Safety of electronic circuits integrated into personal protective equipment (PPE)," Safety Science, vol. 41, no. 5, pp. 395-408, 2003.

[14] ISO 9612:2009 - Acoustics, Determination of Occupational Noise Exposure, Engineering method, 2009.

[15] R. Likert, "A technique for the measurement of attitudes," Archiv für Psychologie, vol. 22, p. 55, 1932.

[16] J. R. Lawson, PASS Sound Muffle Tests Using a Structural Firefighter Protective Ensemble Method, 2009.

[17] NFPA, 1982:2018 Standard on Personal Alert Safety Systems (PASS), 2018.

[18] ISO 7731:2003 Ergonomics, Danger Signals for Public and Work Areas, Auditory danger signals, 2003.

[19] S. Obayashi and J. Zander, "A body-shadowing model for indoor radio communication environments," IEEE Transactions on Antennas and Propagation, vol. 46, no. 6, pp. 920927, 1998.

[20] M. W. Abdullah, X. Fafoutis, E. Mellios, M. Klemm, and G. S. Hilton, "Investigation into off-body links for wrist mounted antennas in bluetooth systems," in 2015 Loughborough Antennas \& Propagation Conference (LAPC), pp. 1-5, Loughborough, UK, November 2015.

[21] S. J. Boyes, Y. Huang, N. Khiabani, P. J. Soh, and G. A. E. Vandenbosch, "Repeatability and uncertainty evaluations of onbody textile antenna efficiency measurements in a reverberation chamber," in 2012 Loughborough Antennas \& Propagation Conference (LAPC), pp. 1-5, Loughborough, UK, November 2012.

[22] H. Zou, H. Jiang, Y. Luo, J. Zhu, X. Lu, and L. Xie, "Bluedetect: an iBeacon-enabled scheme for accurate and energy-efficient indoor-outdoor detection and seamless location-based service," Sensors, vol. 16, no. 2, p. 268, 2016.

[23] S. Bertuletti, A. Cereatti, U. Della, M. Caldara, and M. Galizzi, "Indoor distance estimated from bluetooth low energy signal strength: comparison of regression models," in 2016 IEEE Sensors Applications Symposium (SAS), pp. 1-5, Catania, Italy, April 2016.

[24] G. de Blasio, A. Quesada-Arencibia, C. R. Garcia, J. C. Rodriguez-Rodriguez, and R. Moreno-Diaz, "A protocol-channelbased indoor positioning performance study for bluetooth low energy," IEEE Access, vol. 6, pp. 33440-33450, 2018. 